\title{
CLINICAL SCIENCE
}

\section{Endoscopic ultrasound-guided biopsies for mediastinal lesions and lymph node diagnosis and staging}

\author{
José Celso Ardengh, Ricardo H. Bammann, Matheus de Giovani, Filadelfio Venco, Artur A. Parada \\ Endoscopy Service and Thoracic Surgery Clinic, Hospital 9 de Julho, São Paulo/SP, Brazil.
}

\begin{abstract}
OBJECTIVES: To disseminate transesophageal ultrasound-guided fine needle aspiration (EUS-FNA) as an alternative to investigate mediastinal tumoral lesions because it is an underused modality that has been available in Brazil for more than 15 years.
\end{abstract}

METHODS: Descriptive analysis of a single endoscopy service's experience since 1997 in the accomplishment of EUSFNA for mediastinal staging of previously known malignancies (Group 1) or diagnostic definition of suspect lymph nodes and masses (Group 2).

RESULTS: EUS-FNA was performed in 51 patients between 26 and 87 years of age. The diameter of the lesions ranged between 1.1 and $9.8 \mathrm{~cm}$ (mean $3.9 \mathrm{~cm}$ ). Their location corresponded to the following stations: higher paratracheal (4 cases), lower paratracheal (7), aortic window (12), para-aortic (6), subcarinal (9), paraesophageal (8), and hilar (5). In Group 1, 17 patients had previously diagnosed primary lung (9), breast (4), kidney (2), colon (1), and bladder (1) cancer. Fifteen of these punctures were positive for malignity. Two others were later submitted to mediastinoscopy, which identified metastases not detected by EUS-FNA. Group 2 comprised 34 patients. Among these patients, EUS-FNA diagnosed 22 neoplasms, five cases of tuberculosis and two duplication cysts. Cytology was inconclusive or without a specific diagnosis in five other cases. Mediastinoscopy identified two undiagnosed cases of oat-cell carcinoma, one lymphoma and one cryptococcosis, and confirmed one reactive lymphadenitis. There were no complications related to the method.

CONCLUSIONS: EUS-FNA obviated the need for surgical procedures in $86.3 \%$ of cases. Therefore, oncologists, pulmonologists, and thoracic surgeons should always remember the technique's potential and availability.

KEYWORDS: Endoscopic ultrasound; Mediastinoscopy; Mediastinal Lymphadenopaty; Lung cancer, Staging; Mediastinal Tumor.

Ardengh JC, Bammann RH, Giovani M, Venco F, Parada AA. Endoscopic ultrasound-guided biopsies for mediastinal lesions and lymph node diagnosis and staging. Clinics. 2011;66(9):1579-1583.

Received for publication on March 28, 2011; First review completed on April 26, 2011; Accepted for publication on May 30, 2011

E-mail: jcelso@uol.com.br

Tel.: 5511 5055-7134

\section{INTRODUCTION}

The association between endoscopic techniques and ultrasound first developed in the 1980s. The repercussions and clinical impact of this minimally invasive technological advance have been broadly highlighted in the international scientific literature and more recently expanded to pulmonology and thoracic oncology.

Endobronchial ultrasound (known as EBUS) has faced greater technical bottlenecks, related to the smaller diameters of the bronchoscope, its working channel, the patients' airways and, especially, the interface between the

Copyright (c) 2011 CLINICS - This is an Open Access article distributed under the terms of the Creative Commons Attribution Non-Commercial License (http:// creativecommons.org/licenses/by-nc/3.0/) which permits unrestricted noncommercial use, distribution, and reproduction in any medium, provided the original work is properly cited. ultrasound and air. ${ }^{1}$ The first sectorial echobronchoscope was launched on the international market only in the middle of the first decade of 2000.

Gastrointestinal endosonography (known as EUS), on the other hand, has been in use as a routine procedure for more than 15 years at large hospitals performing high-complexity procedures, including those in Brazil. ${ }^{2-4}$ Its diagnostic and therapeutic range has been well established for pancreatic and pelvic diseases; mediastinal lesions can also be approached through the intrathoracic esophagus. ${ }^{5,6}$ Fineneedle aspiration (FNA) of masses and lymph nodes through the esophageal wall has been performed at specialized centers, with minimal risks of infection or bleeding and without great technical difficulty. ${ }^{5-8}$ The importance and usefulness of EUS for the mediastinal staging of primary lung cancer has been well known since $1996 .{ }^{6}$ The main limitation of EUS is its inability to access the anterior mediastinum because of the interference of air present in the trachea. $1,7,8$ 
This study aims to assess the performance of EUS-guided FNA in diagnosing mediastinal tumor lesions (including lymph node enlargements) and to describe some advantages and particularities of the technique.

\section{MATERIAL AND METHODS}

This observational, retrospective, and cross-sectional experience analysis reports the experience of a single endosonography service linked to a private hospital in Sao Paulo City between February 1997 and January 2011. All clinical data (including copies of radiological and endosonography images) were obtained from the service's computerized database.

The demands for EUS for mediastinal assessment purposes were spontaneous because the patients' own physicians referred them due to pathological findings on chest-Computerized tomography (CT) and, in some more recent cases, on Positron emission tomography (PET) scans.

For the sake of this study, patients were classified into two groups according to the purpose of the examination: Group 1-EUS-FNA performed for mediastinal staging of previously known malignant tumors; and Group 2-EUSFNA performed for diagnostic definition of lymph nodes or suspected mediastinal masses. No technical or logistic differences occurred when the procedure was accomplished in both groups, which always followed the same service routine.

All examinations took place in an outpatient setting, under general anesthesia, starting with conventional upper digestive endoscopy. Then echoendoscopy was used to identify the mediastinal lesions previously detected on radiology exams. Under a direct and real-time ultrasound view, one single lesion (the largest in cases of multiple identified lesions) was punctured with a dedicated 22-gauge endoscopic needle. Once guided into the target lesion, the needle was moved back and forth within the mass while applying suction with a $20-\mathrm{ml}$ syringe. At least three needle punctures were made to obtain adequate tissue specimens. Frozen-section examination was not performed during the procedure in any of the cases. The aspirated material was fixed in formaldehyde and analyzed through the cell-block technique. In case of inconclusive cytopathology results, the patient's physician-in-charge was asked for further information on clinical monitoring, other diagnostic methods, and the respective final diagnosis in each case.

Approval for this study was obtained from the local Institutional Review Board in compliance with the National Health Council Resolution 196/96.

\section{RESULTS}

Out of 1,639 gastrointestinal endosonographies performed during the study period, 51 (3.1\%) looked for mediastinal lesions. This series involved 37 (72.5\%) men and 14 women between 26 and 87 years old (median 65 years). Out of these 51 patients, $23(45.1 \%)$ manifested thoracic symptoms (dysphagia, dyspnea, thoracic pain), 22 (43.1\%) reported nonspecific signs and symptoms (fever and weight loss), and $6(11.8 \%)$ were asymptomatic.

The forwarding physicians included 22 (43.1\%) oncologists, $18(35.3 \%)$ clinical pulmonologists and thoracic surgeons, and 11 (21.6\%) others (general clinicians, digestive surgeons, and cardiologists). It should be highlighted that out of the 51 EUS performed for mediastinal assessment purposes, 23 (45.1\%) happened in the final four years of the research period, and these cases were mostly referred by pulmonologists and thoracic surgeons.

Endoscopic alterations (extrinsic compression) were found in $24(47.1 \%)$ patients, three of whom already displayed esophageal stenosis.

In Group 1 (with previously known malignant disease, forwarded for mediastinal staging), 17 patients were included, 9 with primary lung tumors, 4 with breast tumors, 2 with kidney tumors, 1 with a colon tumor, and 1 with a bladder tumor. Out of these 17 patients, a previous PET scan had been done in only 4 , all of whom were considered "positive" for the suspected mediastinal lesion. The diameter of the punctured lesions ranged from 1.1 to $6.8 \mathrm{~cm}$, with an average of $3.7 \mathrm{~cm}$. Their location (Mountain, 1997) ${ }^{9}$ corresponded to stations 2R (2 cases), 2L (1), 4R (1), 4L (2), \#5 (1), \#6 (1), \#7 (3), \#8 (2), 10R (1), and 10L (3). EUS-FNA demonstrated metastatic involvement in 15 out of $17(88.2 \%)$ patients in Group 1. One case was negative, and another was inconclusive-the respective lymph node stations sampled by EUS were the paraesophageal (\#8) and the left hilar (10L). Both cases were later submitted to classical cervical mediastinoscopy, which identified metastases in lower paratracheal lymph nodes (\#4) that were previously undetected through EUS.

Group 2 (undiagnosed lymph node enlargements or mediastinal masses) comprised 34 patients. The diameter of the punctured lesions varied from 1.6 to $9.8 \mathrm{~cm}$ (average $4.0 \mathrm{~cm}$ ). Their location (Mountain, 1997) ${ }^{9}$ corresponded to stations 2L (one case), 4R (3), 4L (1), \#5 (11), \#6 (5), \#7 (6), \#8 (6), and 10L (1). Among the 34 patients in Group 2, 22 $(64.7 \%)$ "new" tumors were diagnosed through EUS-FNA, including epidermoid carcinoma (10), adenocarcinoma (5), oat-cell (3), lymphoma (2), sarcoma (1), and neuroendocrine carcinoma (1). Other diagnoses established in this group included tuberculosis (5) and duplication cyst (2). Cytology was not malignant (but without a specific diagnosis) in three cases and inconclusive in two others-these five patients were later submitted to mediastinoscopy, which identified two other cases of oat-cell carcinoma, one non-Hodgkin Bcell lymphoma, and one ganglionic cryptococcosis, in addition to confirming one case of non-specific reactive lymphadenitis. Figure 1 displays a flow chart that summarizes the procedures and diagnoses in this study. Figure 2A illustrates a clinical case from Group 1; Figure 2B illustrates a clinical case from Group 2.

There were no complications related to the method.

\section{DISCUSSION}

Despite its technical and commercial availability, EUS is still rather underused in the treatment of thoracic illnesses. Aside from its well-established importance for lung cancer staging, ${ }^{6,10}$ its indication extends to other clinical situations, such as mediastinal lymph node enlargement of unknown causes or primary tumor masses and cystic lesions (for diagnostic or symptom relief purposes). ${ }^{11}$

Considering each patient's final diagnosis as the gold standard, the general sensitivity of EUS-FNA in our study was $88.0 \%$, with $11.7 \%$ false negative cases. These rates still apply if the sample is limited to the 17 cases in Group 1. In a recent meta-analysis ${ }^{6}$ restricted to lung cancer cases, the general EUS-FNA sensitivity was $84 \%$ for metastasis 


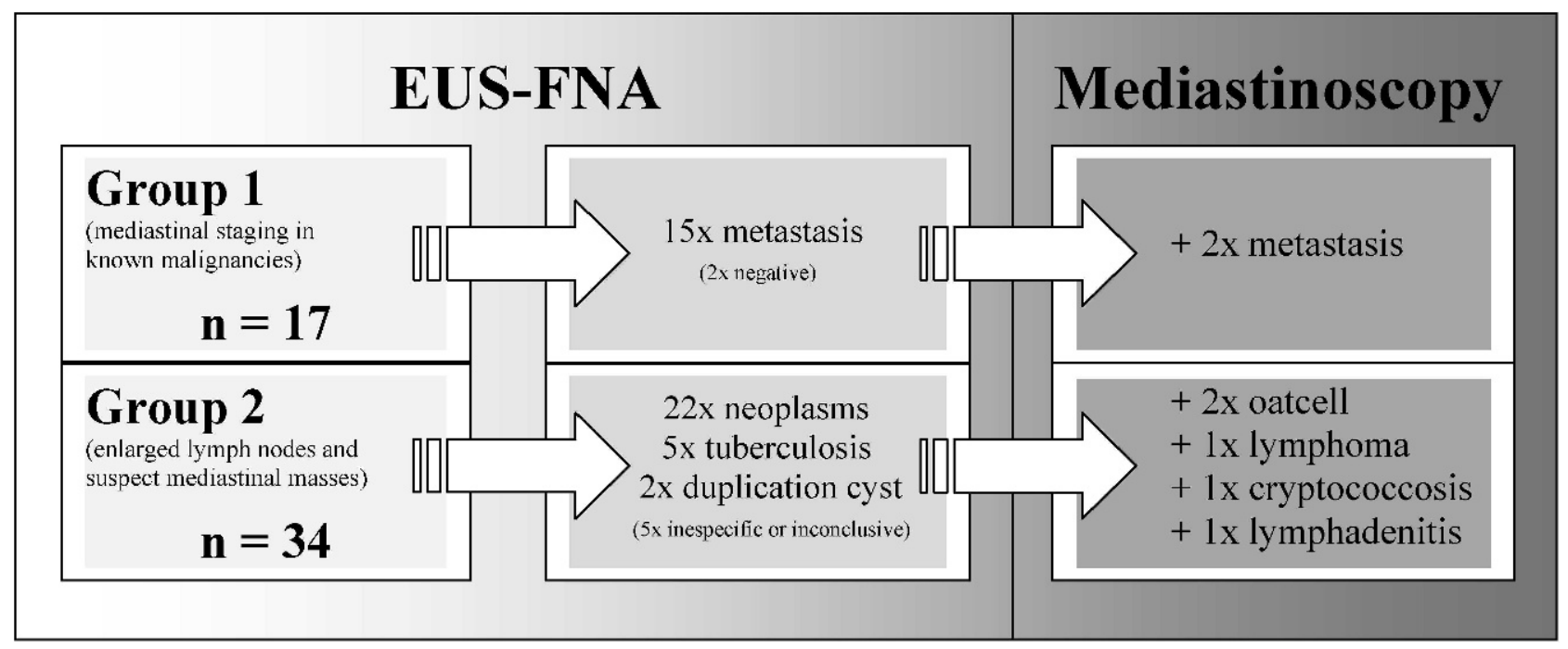

Figure 1 - Endoscopic ultrasound-guided fine-needle aspiration (EUS-FNA) results and complementary mediastinoscopy performed in 51 patients.

detection (N2 and/or N3), with a global false-negative rate of $19 \%$.

The only other Brazilian publication found that addressed this issue ${ }^{12}$ assessed 25 EUS-FNA performed for the sake of diagnostic clarification of mediastinal masses and lymph nodes. Most (48\%) lesions were neoplastic, while $24 \%$ were inflammatory or infectious. Normal lymphatic tissue was obtained in three cases (12\%) and, in four others $(16 \%)$, insufficient material was sampled. No data are available on other complementary methods used to define the diagnosis for inconclusive cases.

The comparison between different methods (EUS, EBUS, and surgical mediastinoscopy) in mediastinal staging for primary lung cancer has been a recurrent and widely discussed theme. This technical choice depends, among other factors, on the patient's clinical condition, the degree of suspected mediastinal involvement, the location of the primary tumor, the histological type, diameter and level of the biopsied lymph nodes, the number of samples obtained and, most importantly, the availability of different methods at each institution, as well as the respective results the local team has achieved. ${ }^{6,13}$

A larger number of recent EUS have been performed at the request of chest physicians-we believe this change resulted from these specialists' recent contact with the largescale dissemination of EBUS in the international literature, particularly regarding clinical repercussions. Both EUS and EBUS are recommended by the main thoracic oncology guidelines on the invasive mediastinal staging of primary lung cancer. ${ }^{6,14,15}$

Yet other facts and peculiarities should be reminded:

- Any invasive sampling method is more specific than CT scan and PET scan alone. ${ }^{16}$

- The association between EUS and EBUS in the same patient reaches accuracy levels of more than $95 \% .{ }^{17,18}$ These rates are quite encouraging, but combining both sets of equipment, logistics, training, and the availability of human and technical resources can hardly be justified in commercial terms.
- Mediastinoscopy continues to be an obligatory complementary method whenever the above techniques reveal a negative result. ${ }^{6,14,15}$ Some authors defend the position that if the main goal is the diagnostic confirmation of suspected metastatic disease detected through CT or PET scan, then endosonography methods (EUS and/or EBUS), if available, are an excellent alternative, with high sensitivity and low morbidity levels. However, if the main goal of invasive staging is to confirm the absence of mediastinal involvement, in most cases, surgical mediastinoscopy seems to be the best option. ${ }^{13}$

Based on Mountain's former lymph node map ${ }^{9}$ (which was the gold standard used during the study period), EUS can assess and obtain samples from the upper and lower paratracheal levels (stations \#2 and \#4), aortic window (\#5), subcarinal level (\#7), paraesophageal level (\#8), inferior pulmonary ligament (\#9), and pulmonary hilum (\#10). It should be noted that EUS also permits staging (and biopsying) of primary pulmonary lesions when located near (or eventually invading) the mediastinum. ${ }^{19}$ It has also been capable of detecting (and biopsying) metastatic disease in subdiaphragmatic lesions, such as those affecting the left adrenal gland, celiac lymph nodes, and liver. 6,8

The experience reported here includes a considerable number (six cases) of samples obtained from the para-aortic level (station \#6), which deserves more careful and detailed analysis. Strictly speaking, station \#6 corresponds to the lymph nodes anterior and lateral to the ascending aorta, between a line tangent to the superior border and another to the inferior border of the aortic arch. ${ }^{9}$ Hence, although station \#6 can indeed be visualized through EUS, it is rather difficult to obtain samples through the esophageal route, as that would imply transection of the pulmonary artery or the aorta itself with the puncture needle. This location may therefore have not been very precise under the EUS view, so that some lymph nodes attributed to the para-aortic position (if not all of them) may include lesions from stations $4 \mathrm{~L}, \# 5$ and even \#8.

Because esophageal endosonography does not offer easy anatomical reference points, the endoscopist's experience 

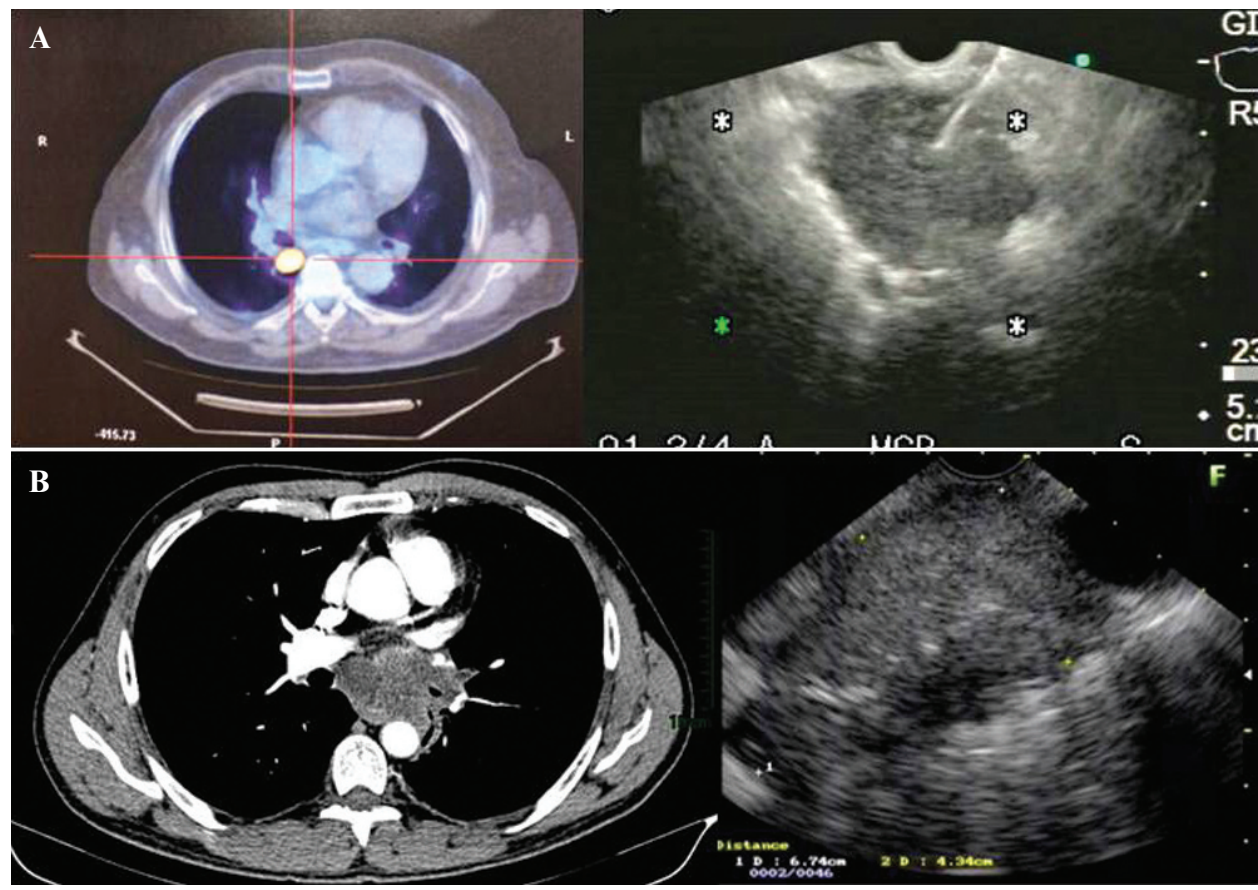

Figure 2 - A A PET scan shows a 2-cm hypermetabolic lymph node (station 10R) in an 81-year-old male patient who had already been submitted to a lower right lobe segmentectomy (adenocarcinoma) 18 months prior. EUS-FNA (notice the needle piercing the lesion) demonstrated metastatic disease. B A 46-year-old male presented chronic cough attributed to gastroesophageal reflux. Subsequent hoarseness led to a CT scan that showed a large mediastinal mass in the subcarinal and paraesophageal stations. EUS-FNA was effectively used to diagnose epidermoid carcinoma.

and knowledge of regional topography are fundamental for a successful examination. Identifying and sampling lesions located at the subcarinal level (\#7), for example, will hardly represent any difficulty because of its central position, which is always anterior to the middle esophagus. It is known that FNA of station \#7 guided by endosonography techniques (both EUS and EBUS) does not obtain better results than a simple, "blind" transtracheal puncture. ${ }^{20}$ The pulmonary hilar levels (\#10), on the other hand, are frequently mixed up with the inferior paratracheal stations (\#4), especially on the right. Such inadequate staging can radically change therapeutic decisions-this means a possible N2 false-positive result. In lung cancer patients, if the lymph nodes of stations $10 \mathrm{R} / \mathrm{L}$ (classified as N1) are unintentionally interpreted as belonging to stations $4 \mathrm{R} / \mathrm{L}$ (classified as N2), a malignant aspirate may exclude the option for a radical surgical resection and the potential for cure. ${ }^{8,13}$

There are further issues related to the routine adopted at our service, which remains limited to the puncturing of a single suspect lesion (the largest in case of multiple identified lesions). Hence, it is recommended that, in all cases, samples be obtained from at least two lymph node zones as recently mapped by the International Association for the Study of Lung Cancer (IALSC), ${ }^{21}$ always including the subcarinal zone (station \#7), to improve prognostic definitions.

Equipment costs (especially disposable needles) and the learning curve for use of the technique are highlighted as the main difficulties that EBUS will still have to face before achieving greater availability and widespread use. ${ }^{1}$ International and Brazilian experiences with EUS-FNA, on the other hand, have already demonstrated the method's ability to avoid surgical procedures (mediastinoscopy, videothoracoscopy or even exploratory thoracotomy) in a considerable number of patients- $86.3 \%$ of cases in this study.

\section{CONCLUSION}

EUS-FNA is an excellent alternative for mediastinal lesion diagnosis and staging. Not only endoscopists but also oncologists, pulmonologists, and thoracic surgeons should consider its reliable potential and current availability.

\section{REFERENCES}

1. Bugalho A, Doris MK, Hamacher J, Eberhardt R, Herth FJ. Ecoendoscopia brônquica: aspectos práticos e aplicabilidade clínica. Rev Port Pneumol. 2008;14:55-88.

2. Ardengh JC, Paulo GA, Ferrari Jr AP. Pancreatic carcinomas smaller than $3.0 \mathrm{~cm}$ : endosonography (EUS) in diagnosis, staging and prediction of resectability. HPB (Oxford). 2003;5:226-30.

3. Ardengh JC, Paulo GA, Ferrari Jr AP. EUS-guided FNA in the diagnosis of pancreatic neuroendocrine tumors before surgery. Gastrointestinal Endoscopy. 2004;60:381-4.

4. Silva AF, Moura EGH, Artifon ELA, Sakai P, Maluf-Filho F, Matuguma $\mathrm{SE}$, et al. Effectiveness of the echoendoscopic puncture in the diagnosis of solid pancreatic mass. ABCD Arq Bras Cir Dig. 2009;22:192-6.

5. Maluf-Filho F, Dotti CM, Farias AQ, Kupski C, Chaves DM, Artifon E, et al. I Consenso Brasileiro de Ecoendoscopia. Arq Gastroenterol. 2007;44:353-8, doi: 10.1590/S0004-28032007000400014.

6. Detterbeck FC, Jantz MA, Wallace M, Vansteenkiste J, Silvestri GA. Invasive mediastinal staging of lung cancer. ACCP evidence-based clinical practice guidelines (2nd edition). Chest. 2007;132:202S-220S, doi: 10.1378/chest.07-1362.

7. Larsen SS, Krasnik M, Vilmann P, Jacobsen GK, Pedersen JH, Faurschou $\mathrm{P}$, et al. Endoscopic ultrasound guided biopsy of mediastinal lesions has a major impact on patient management. Thorax. 2002;57:98-103, doi: 10 . 1136/thorax.57.2.98.

8. Annema JT, Veersteegh MI, Veselic M, Welker L, Mauad T, Sont JK, et al. Endoscopic ultrasound added to mediastinoscopy for preoperative 
staging of patients with lung cancer. JAMA. 2005;294:931-6, doi: 10 . 1001/jama.294.8.931.

9. Mountain CF, Dresler CM. Regional lymph node classification for lung cancer staging. Chest. 1997;111:1718-23, doi: 10.1378/chest.111.6.1718.

10. Cerfolio RJ, Bryant AS, Eloubeidi MA. Routine Mediastinoscopy and Esophageal Ultrasound Fine-Needle Aspiration in Patients With Non-small Cell Lung Cancer Who Are Clinically N2 Negative. Chest. 2006;130:1791-5, doi: 10.1378/chest.130.6.1791.

11. Wildi SM, Hoda RS, Fickling W, Schmulewitz N, Varadarajulu S, Roberts SS, et al. Diagnosis of benign cysts of the mediastinum: the role and risks of EUS-FNA. Gastrointest Endosc. 2003;58:362-8.

12. Roldan LF, Artifon ELA, Maluf-Filho F, Chaves DM, Matuguma SE, Souza TF, et al. Ecopunção endoscópica no diagnóstico das massas mediastinais: análise de 25 casos. GED Gastroenterol Endosc Dig. 2006;25:1-4.

13. Toloza EM, Harpole L, Detterbeck F, McCrory DC. Invasive Staging of Non-small Cell Lung Cancer: A Review of the Current Evidence. Chest. 2003;123:157S-166S, doi: 10.1378/chest.123.1_suppl.157S.

14. National Comprehensive Cancer Network (NCCN). Clinical Practice Guidelines in Oncology. V.2.2010. http:/ / www.nccn.org/professionals/ physician_gls/PDF/nscl.pdf Accessed September 10, 2010.

15. De Leyn P, Lardinois D, Van Schil PE, Rami-Porta R, Passlick B, Zielinski M, et al. ESTS guidelines for preoperative lymph node staging for non-small cell lung cancer. Eur J Cardiothorac Surg. 2007;32:1-8, doi: 10.1016/j.ejcts. 2007.01.075.
16. Yasufuku K, Nakajima T, Motoori K, Sekine Y, Shibuya K, Hiroshima K, et al. Comparison of endobronchial ultrasound, positron emission tomography and CT for lymph node staging of lung cancer. Chest. 2006;130:710-8, doi: 10.1378/chest.130.3.710.

17. Herth FJ, Lunn W, Eberhardt R, Becker HD, Ernst A. Transbronchial versus transesophageal ultrasound-guided aspiration of enlarged mediastinal lymph nodes. Am J Respir Crit Care Med. 2005;171:1164-7, doi: 10.1164/rccm.200411-1560OC.

18. Rintoul RC, Skwarski KM, Murchison JT, Wallace WA, Walker WS, Penman ID. Endobronchial and endoscopic ultrasound-guided real-time fine-needle aspiration for mediastinal staging. Eur Respir J. 2005;25:41621, doi: 10.1183/09031936.05.00095404.

19. Varadarajulu S, Schmulewitz N, Wildi SM, Roberts S, Ravenel J, Reed CE, et al. Accuracy of EUS in staging of T4 lung cancer. Gastrointest Endosc. 2004;59:345-8, doi: 10.1016/S0016-5107(03)02541-0.

20. Herth F, Becker H, Ernst A. Conventional vs Endobronchial UltrasoundGuided Transbronchial Needle Aspiration: a Randomized Trial. Chest. 2004;125:322-5, doi: 10.1378/chest.125.1.322.

21. Rusch VW, Asamura H, Watanabe H, Giroux DJ, Rami-Porta R Goldstraw P. The IASLC Lung Cancer Staging Project - a proposal for a new International Lymph Node Map in the forthcoming seventh edition of the TNM Classification for Lung Cancer. J Thorac Oncol. 2009;4:568-77, doi: 10.1097/JTO.0b013e3181a0d82e. 